\title{
Understanding autonomous vehicles: A systematic literature re- view on capability, impact, planning and policy
}

\author{
Asif Faisal \\ Queensland University of Technology \\ asifiqbalmohammad.faisal@hdr.qut.edu.au \\ Md Kamruzzaman \\ Monash University \\ md.kamruzzaman@monash.edu
}

\author{
Tan Yigitcanlar \\ Queensland University of Technology \\ tan.yigitcanlar@qut.edu.au \\ Graham Currie \\ Monash University \\ graham.currie@monash.edu
}

\begin{abstract}
Advancement in automated driving technology has created opportunities for smart urban mobility. Automated vehicles are now a popular topic with the rise of the smart city agenda. However, legislators, urban administrators, policymakers, and planners are unprepared to deal with the possible disruption of autonomous vehicles, which potentially could replace conventional transport. There is a lack of knowledge on how the new capabilities will disrupt and which policy strategies are needed to address such disruption. This paper aims to determine where we are, where we are headed, what the likely impacts of a wider uptake could be, and what needs to be done to generate desired smart urban mobility outcomes. The methodology includes a systematic review of the existing evidence base to understand capability, impact, planning, and policy issues associated with autonomous vehicles. The review reveals the trajectories of technological development, disruptive effects caused by such development, strategies to address the disruptions, and possible gaps in the literature. The paper develops a framework outlining the inter-links among driving forces, uptake factors, impacts and possible interventions. It concludes by advocating the necessity of preparing our cities for autonomous vehicles, although a wider uptake may take quite some time.
\end{abstract}

\section{Article history:}

Received: March 28, 2018

Received in revised form:

November 6, 2018

Accepted: November 6, 2018

Available online: January 28,

2019

\section{Introduction}

The convergence of technology and the city is seen as a possible remedy to overcome the challenges of urbanization such as climate change, congestion, and greenhouse gas (GHG) emissions (Yigitcanlar, 2016). Transport, as an integral part of the city, is responsible for about a quarter to one-third of GHG emissions (Kamruzzaman, Hine, \& Yigicanlar, 2015; Arbolino, Carlucci, Cira, Loppolo, \& Yigicanlar, 2017; Yigitcanlar, Foth, \& Kamruzzaman, 2018). Technology in the name of smart urban mobility is

Copyright 2019 Asif Faisal, Tan Yigitcanlar, Md Kamruzzaman \& Graham Currie http://dx.doi.org/10.5198/jtlu.2019.1405

ISSN: 1938-7849 | Licensed under the Creative Commons Attribution - Noncommercial License 4.0

The Journal of Transport and Land Use is the official journal of the World Society for Transport and Land Use (WSTLUR) and is published and sponsored by the University of Minnesota Center for Transportation Studies. 
becoming a key concept of the contemporary urban policy agenda to address the undesirable effects of transport (Creutzig et al., 2015; Perveen, Yigicanlar, Kamruzzaman, \& Hayes, 2017; Perveen, Kamruzzaman, \& Yigicanlar, 2017, 2018; Yigitcanlar \& Kamruzzaman, 2018b).

As originally conceived within the smart cities agenda (Yigitcanlar, 2015; Lara, Costa Furlani, \& Yiticanlaar, 2016; Trindade et al., 2017; Chang, Sabatini-Marques, da Costa, Selig, \& Yigicanlar, 2018; Yigitcanlar et al., 2018a), the smart urban mobility concept is characterized by an integration of sustainable and smart vehicular technologies, and cooperative intelligent transport systems (ITS) through cloud-servers and big-data-based vehicular networks (Kim, Moom, \& Suh, 2015). In other words, smart urban mobility is conceptualized as urban traffic services combined with smart technologies (Chun \& Lee, 2015). Undoubtedly one of the most advanced applications that utilizes numerous ITS tools as a part of the smart urban transport system is autonomous vehicle (AV) —a.k.a. automated car, self-driving car or driverless car (Spyropoulou, Penttinen, Karlaftis, Vaa, \& Golias, 2008; Chong et al., 2013; Olaverri-Monreal, 2016).

The basic concept of road vehicle automation refers to the replacement of some or all of the human labor of driving by electronic and/or mechanical devices (Shladover, 2018). Origins of the automated driving technology can be traced back to the early 20th century. At that time, the technology was concentrated on autonomous speed, break, lane control, and other basic cruise control aspects (Shladover, Su, \& Lu, 2012; Anderson et al., 2014; Arnaout \& Arnaout, 2014; Pendleton et al., 2017). However, only during the last decade or so, incubating conditions of the Digital and 4th Industrial Revolutions gave birth to rapid technological advancements in the field; resulting in numerous prototype AVs being trailed on the roads (Christie, Koymans, Chanard, Lasgouttes, \& Kaufmann, 2016).

Many research articles have been published in the academic literature describing the technological advancement of AVs (Denaro, Zmud, Shladover, Smith, \& Lappin, 2014). However, academic literature outlining the $\mathrm{AV}$ induced disruptions (both positive and negative) in cities and how policies are being introduced to promote or address various disruptive effects is fairly limited (Bagloee, Tavana, Asadi, \& Oliver, 2016; Gruel \& Stanford, 2016; Truong, De Gruyter, Currie, \& Delbosc, 2017), despite a recent prediction suggests that by 2045, AVs would account for up to half of all road travel (Bansal \& Kockelman, 2017; Litman, 2017). Even more so, there is no study, to our knowledge, in the academic literature that critically scrutinizes the state of AVs from a combined perspective focusing on its capability, impact and existing/potential policy interventions to reduce/foster the disruptive effects.

Against this backdrop, this paper aims to determine where we are at, where we are headed to, what the likely impacts of wider AV uptake could be, and what needs to be done for AVs to generate desired smart urban mobility outcomes - with a particular focus on the capability, impact and policy. In order to achieve this aim, the study undertakes a systematic review of the literature on AVs published in peerreviewed journals. The review concentrates on the following research objectives: (a) Highlighting the main findings and contributions of the reviewed literature; (b) Mapping out the relationships among the capability, impact, planning interventions, and pre-deployment policy to accommodate AVs as well as to reduce the undesirable effects of AVs; (c) Determining the gaps in the literature and pointing out directions for prospective research. A key outcome of this research is the development of an AV driving forces, uptake factors, impacts and interventions framework. 


\section{Autonomous vehicles in a nutshell}

\subsection{Historical background}

Vehicle automation was originally envisioned as early as in 1918 (Pendleton et al., 2017), and the first concept of automated vehicle was exhibited by General Motors in 1939 (Shladover, 2018). The initial phase of research and development $(\mathrm{R} \& \mathrm{D})$ was jointly initiated by General Motors and Radio Corporation of America Sarnoff Laboratory in the 1950s (Shladover, 2018). From 1964 to 2003, several other $\mathrm{R} \& \mathrm{D}$ programs were operational in the US, Europe, and Japan under individual and joint initiatives of different government institutes and academia to develop automated bus and truck platoons, supersmart vehicle systems, and video image processing of driving scene recognition (Shladover, 2018). AV research was accelerated through the Defense Advanced Research Projects Agency's (DARPA) Grand Challenges Program in the US in 2004. The challenges resulted in AVs capable of traversing dessert terrain in 2005, and in 2007. Researchers also managed to place AVs on urban roads through the DARPA's Urban Challenge Program (Pendleton et al., 2017; Shladover, 2018). Since then, R\&D continued at a fast pace in both academia and industrial settings.

Volvo, for instance, started its journey to autonomous driving in 2006, introduced its full autonomous test vehicle in 2017, and has plans to bring its unsupervised AV to the market by 2021. Tech giant Google started its journey towards full AVs in 2009, and by 2017 Google's AV fleet, WAYMO, has completed three million miles driving within four US states. In 2014, TESLA announced that its car will be capable of self-driving about $90 \%$ of the time. Today, all TESLA models are equipped with self-driving capability. By 2020, Audi, BMW, Mercedes-Benz and Nissan are expecting to have their AVs in the market.

Bloomberg (2017) provides an inventory of how cities around the globe are preparing for the transition to a world with AVs. According to this study, 36 cities were hosting AV tests, or have committed to doing so in the near future; where 18 other cities are undertaking long-range surveys of the regulatory, planning, and governance issues associated with AVs, but have not yet started piloting. The inventory considers of those piloting cities that were partnering on tests of a variety of AV products, including retrofitted autos and brand-new vehicles like conveyors (small, cart-sized AVs that travel on sidewalks). Testbed locations are generally isolated places from the rest of the city, such as technology parks, college campuses, urban renewal districts, highways, and former international mega-event sites. Therefore, as stated by Bloomberg (2017), while these trials are happening, they are not yet tackling the full challenges of navigating through complex urban environments. Table 1 lists the cities that are piloting (hosting AV tests or have committed to doing so in the near future) or preparing (undertaking long-range surveys of the regulatory, planning, and governance issues raised by $\mathrm{AVs}$, but have not yet started piloting) themselves for an AV uptake. 
Table 1. List of cities testing or in preparation for AVs (Bloomberg, 2017)

\begin{tabular}{ccc}
\hline Piloting cities & Piloting cities (continued) & Preparing cities \\
\hline Adelaide, AU & Melbourne, AU & Auckland, NZ \\
Amsterdam, NL & Oslo, NO & Buenos Aires, AR \\
Austin, US & Paris, FR & Cambridge, US \\
Boston, US & Pittsburgh, US & Columbus, US \\
Bristol, UK & Reno, US & Denver, US \\
Chandler, US & Rotterdam, NL & Dublin, US \\
Chiba City, JP & San Antonio, US & Los Angeles, US \\
Detroit, US & San Francisco, US & Montréal, CA \\
Dubai, UAE & San Jose, US & Nashville, US \\
Edmonton, CA & Seongnam, KR & Orlando, US \\
Eindhoven, NL & Singapore & Palo Alto, US \\
Gothenburg, SE & Toronto, CA & Portland, US \\
Haarlem, NL & Wageningen, NL & Rionegro, CO \\
Helsinki, FI & Washington, DC, US & Sacramento, US \\
Las Vegas, US & West Midlands, UK & Santa Monica, US \\
London, UK & Wuhan, CN & Seattle, US \\
Lyon, FR & Wuhu, CN & Sáo Paulo, BR \\
Milton Keynes, UK & Zhuzhou, CN & Tel Aviv, IL \\
\hline
\end{tabular}

\subsection{Autonomous technology}

In line with the automation concept, a taxonomy of 4-level of vehicle automation was developed by the National Highway Traffic Safety Administration (NHTSA) in 2013 (Wadud, MaKenzie, \& Leiby, 2016), and a 5-level automation was introduced by the Society of Automotive Engineers International (SAE) in 2014 - later on updated in 2016 (Coppola \& Morisio, 2016; SAE, 2016a, 2016b; Snyder, 2016; Milakis, van Arem, \& van Wee, 2017). In 2016, NHTSA adopted SAE's taxonomy and automation levels (NHTSA, 2016). SAE's taxonomy and automation levels have become an industry standard, and also frequently referred in the academic literature (Rubin, 2016; Scheltes \& de Almeida Correia, 2017; Walker \& Marchau, 2017; Shladover, 2018). Table 2 describes the operational functions included in automated driving system (ADS), and the role of human driver at each level of vehicle automation. 
Table 2. Taxonomy of road vehicle automation derived from SAE (2016a)

\begin{tabular}{|c|c|c|c|c|}
\hline \multirow[t]{2}{*}{ Level of automation } & \multicolumn{2}{|l|}{ Automated driving system } & \multicolumn{2}{|l|}{ Human driver } \\
\hline & Operational function & Capability & $\begin{array}{l}\text { Operational } \\
\text { function }\end{array}$ & Capability \\
\hline $\begin{array}{l}\text { Level } 1 \\
\text { (most functions are } \\
\text { controlled by driver) }\end{array}$ & $\begin{array}{l}\text { Control: lateral and longi- } \\
\text { tudinal }\end{array}$ & In some driving modes & $\begin{array}{l}\text { Localisation } \\
\text { Perception } \\
\text { Planning } \\
\text { Management }\end{array}$ & In all driving modes \\
\hline $\begin{array}{l}\text { Level } 2 \\
\text { (at least one driver } \\
\text { assistance system is } \\
\text { automated) }\end{array}$ & $\begin{array}{l}\text { Control: lateral and longi- } \\
\text { tudinal }\end{array}$ & In some driving modes & $\begin{array}{l}\text { Localisation } \\
\text { Perception } \\
\text { Planning } \\
\text { Management }\end{array}$ & In all driving modes \\
\hline $\begin{array}{l}\text { Level } 3 \\
\text { (driver is able to shift } \\
\text { safety-critical functions } \\
\text { to vehicle) }\end{array}$ & $\begin{array}{l}\text { Control: lateral and longi- } \\
\text { tudinal } \\
\text { Localisation } \\
\text { Perception } \\
\text { Planning }\end{array}$ & In some driving modes & Management & In all driving modes \\
\hline $\begin{array}{l}\text { Level } 4 \\
\text { (fully-autonomous, } \\
\text { but not in every driv- } \\
\text { ing scenario) }\end{array}$ & $\begin{array}{l}\text { Control: lateral and longi- } \\
\text { tudinal } \\
\text { Localisation } \\
\text { Perception } \\
\text { Planning } \\
\text { Management }\end{array}$ & In some driving modes & $\mathrm{n} / \mathrm{a}$ & $\mathrm{n} / \mathrm{a}$ \\
\hline $\begin{array}{l}\text { Level } 5 \\
\text { (fully-autonomous, } \\
\text { vehicle's performance } \\
\text { is equal that of human } \\
\text { driver in every driving } \\
\text { scenario) }\end{array}$ & $\begin{array}{l}\text { Control: lateral and longi- } \\
\text { tudinal } \\
\text { Localisation } \\
\text { Perception } \\
\text { Planning } \\
\text { Management }\end{array}$ & In all driving modes & $\mathrm{n} / \mathrm{a}$ & $\mathrm{n} / \mathrm{a}$ \\
\hline
\end{tabular}

In theory, an automated vehicle system can only be termed as an "autonomous" system, when all the dynamic driving tasks, at all driving environment, can be performed by the vehicle's automated system. According to the Federal Automated Vehicles Policy of the US Department of Transportation, a vehicle is denoted as AV if it has levels 3-5 automated systems (DoT, 2016). However, these levels of autonomy are not strictly maintained in the literature and any level of autonomy is referred to as autonomous (Shladover, 2018). Throughout this paper, the term AV will refer to the levels 3-5 automated systems only.

Driving requires a variety of functions, including localization, perception, planning, control, and management (Coppola \& Morisio, 2016). Information acquisition is a prerequisite to localization, and perception. If all of these functions, including information acquisition, are available in a vehicle, it could definitely be termed as an AV. If any AV has to communicate with other infrastructures to collect information, or to negotiate its maneuvers, it is termed as connected autonomous vehicle (CAV) (Shladover, 2018), and when any manually driven vehicle, whether manual or automated, has to communicate with other infrastructures to collect information, or to negotiate its maneuvers, it is termed as connected vehicle (CV) (Hendrickson, Biehler, \& Mashayekh, 2014; Coppola \& Morisio, 2016). Therefore, CV technology is complimentary or has synergistic effect on the implementation of AV to some extent (Shladover, 2018), though connectivity is not a mandatory feature of AVs (Hendrickson et al., 2014). 


\subsection{Perceived benefits}

AVs are expected to be operational both as private and as commercial vehicle (Heinrichs, 2016; Collingwood, 2017; Wadud, 2017). One of the perceived advantages and flexibility of autonomous private car over the conventional private car is that it can simultaneously be used among all members in a family. Commercial AVs could be operated as taxi, bus, and freight services. AV taxis can provide service as a combination of conventional car-sharing and taxi services, which is referred to as shared AV (SAV) or driverless taxi (Fagnant \& Kockelman, 2014; Krueger, Rashidi, \& Rose, 2016).

Perception prevails that driverless taxi is likely to complement/supplement traditional public transit service, and it can potentially replace the private car and conventional taxis because SAVs are expected to be relatively inexpensive and facilitating opportunity for multitasking during a ride (Malokin, Circella, \& Mokhtarian, 2015; Krueger et al., 2016; Milakis, Snelder, van Arem, Homem, \& van Wee, 2017). In spite of having cooperation within the fleet, conventional taxi drivers seek to maximize individual profit, overruling minimum wait time and less passenger kilometers travelled (PKT), as identified by the fleet cooperation (Boesch, Ciari, \& Axhausen, 2016).

Some transport network companies (TNC), such as Uber and Lyft, have been trying to develop a model similar to SAVs in their operations. However, in this model, human drivers are still responsible for routing, relocation, operation times, and many other decision-making factors. On the contrary, $100 \%$ central control system of SAV can overcome the limitations of conventional taxi services. Thus, SAV can ensure more system-optimal and overall profit-maximizing network with a higher service level and lower empty travel cost with respect to conventional taxi services, and TNCs (Fagnant, Kockelman, \& Bansal, 2015). With a comprehensive ICT integration, SAV could facilitate dynamic ridesharing (DRS). Hence, SAV can either provide service with DRS or without DRS facility (Krueger et al., 2016).

The barriers to traditional ridesharing service could be overcome through the introduction of DRS (Krueger et al., 2016) or driverless taxi (Martinez \& Viegas, 2017). The concept of "mobility-as-aservice" (MaaS) can also be accommodated with the introduction of SAV and DRS. Commercial operations like taxi, bus and freight service can benefit from automation through the postponement of driver costs (Wadud, 2017). Deployment of autonomous private car or taxi may reduce parking demand at urban core locations, repurposing those spaces for the use of other economic activity and in turn, it may act to increase urban density in central business district (CBD) locations (Bagloee et al., 2016; Levine, Segev, \& Thode, 2017).

In contrast, reliability, comfort, and reduced perceived value of time may encourage long commute distances, contributing to urban sprawl and influencing real-estate values in ex-urban areas (Heinrichs, 2016; Rubin, 2016; Snyder, 2016). Integration of platooning features in freight and bus services, with the help of autonomous and cooperative technology, can play a vital role in increasing road capacity. These are few prominent and divergent examples of AV, considering its diversity in use.

The technological advancement and potential benefits of $\mathrm{AVs}$, as discussed above, are linked together (Heinrichs, 2016). How are these benefits likely to be translated in the form and structure of urban systems? This research compiles evidence from published literature to address this question.

\section{$3 \quad$ Methodology}

This research applies a systematic review of the literature to achieve the research aim and objectives. A systematic literature review follows an explicit protocol for higher data reliability and for shaping the diversity of knowledge in a specific research field (Rowley \& Slack, 2004; Brereton, Kitchenham, Budgen, Turner, \& Khalil, 2007; Bask \& Rajahonka, 2017). It aims at abating bias through comprehensive literature searches and delivers an evaluation trajectory for the reviewer verdicts, procedures and inferences (Burgess, Singh, \& Koroglu, 2006; Bask \& Rajahonka, 2017). The review involves three major 
activities: (a) Planning; (b) Realization or review; (c) Reporting and presentation (Tranfield, Denyer, \& Smart, 2003; Bask \& Rajahonka, 2017; Oliveira et al., 2017).

The above three activities were undertaken according to the methodological principles recommended by Oliveira, Márcio de Almeida et al. (2016) and Oliveria, Albergaria De Mello Bandeira et al. (2017): (a) Planning activity consists of identifying the need for revision (why), purpose of the review (what), and developing the protocol of the review (how, when and where); (b) Review activity including identification, selection, and inclusion of papers, evaluation of the selected papers, extraction of data and information, and synthesis of data; (c) Reporting and presentation includes preparing reports, and presenting results.

Firstly, a research plan involving the research aim and objectives, keywords, and a set of inclusion and exclusion criteria was developed. Research objectives were framed, to explore links among various aspects of $A V s$ and thus to recognize promising areas for future research. As the keyword, we decided to use "autonomous vehicle" OR "automated vehicle" OR "driverless car" OR "self-driving car". To focus on the research objectives, we identified the inclusion criteria - peer-reviewed research articles in English language. An online search was conducted using a university library search engine that connects to 393 different databases including ScienceDirect, Scopus, Web of Science, Wiley online library, directory of open access journals (DOAJ), and so on. Edited or authored books, articles published in other languages, grey literature such as government or industry reports and non-academic research, and editorial papers were not included in the review. The search included only peer-reviewed and full text journal articles available online-procedia papers are considered as journal articles, due to relatively limited numbers of journal articles published on the topic.

Secondly, the search was conducted in January 2018 for journal articles published between January 2000 and January 2018. The review focused on the post-2000 articles due to limited studies focused on AVs prior to this date-particularly on the impact, planning and policy issues. Several thematic searches were specified through a combination of multiple keywords. The keywords used in all thematic searches were divided into two parts: The first part (specified by first parentheses) was directed to the title of the articles, and the second part was directed to the abstract. The resultant search items were initially checked by reading the abstract and then by reading the full-text in order to verify their scope against the research objectives.

The first thematic search was conducted using the search tag of ("autonomous vehicle" OR "automated vehicle" OR "driverless car" OR "self-driving car") AND ("control” OR "management" OR "localization" OR "lane change" OR "maneuver" OR "platooning" OR "merging" OR "crash avoidance" OR "cruise control" OR "navigation" OR "car-sharing" OR "multitasking" OR "valet parking” OR "capabilities" OR "features") to identify studies that focus on the AV capabilities. The search resulted in 616 papers, which were reduced to 49 articles after checking the abstract and further reduced to 16 articles after reading the full-text.

The next thematic search was conducted using the search tag of ("autonomous vehicle" OR "automated vehicle" OR "driverless car" OR "self-driving car") AND ("influence" OR "impact" OR "implication" OR "effect" OR "planning") keywords to identify articles that focus on the AV impacts. The search resulted in 154 papers. We have gone through the abstracts of these papers and limited the selection to 51 articles. After reading the full papers to make sure that they actually fit into our scope of interest, the selection was limited to 33 journal articles.

We conducted next search in the database using the search tag of ("autonomous vehicle" OR "automated vehicle" OR "driverless car" OR "self-driving car") AND ("policy" OR "law" OR "legislation" OR "legal") to identify papers that focus on the AV policies. The search resulted in 159 papers in total, which were screened through by reading the abstract (resulted in 29 articles) and full-text (resulted in 12 articles). 
In total, 61 journal articles (peer-reviewed and full text available online) fulfilled our selection criteria, and these papers were then read again and reviewed. Following the selection, we categorized the reviewed papers according to subthemes. Then, we extracted data from the reviewed papers in tables, formulated according to the three subthemes (Appendix Tables A-C). Each table contained the following information against each of the selected article: name of authors, year of publication, title of the article, name of the journal, research aim/objectives, theoretical perspective/framework, method, and main findings.

Then, we discussed and linked up the individual findings of each subtheme into one. Some reviewed papers were discarded at this stage that did not match directly with the subthemes. This helped us to understand where we are at, where we are headed to, what the likely impacts of wider AV uptake are, and what needs to be done for AV to generate desired smart urban mobility outcomes.

The final stage of the review process was to write up and present our findings in the format of a literature review paper. In this process, some relevant literature, although not meeting the pre-determined selection criteria, are included as supporting material to better appreciate the background context and discuss the findings-e.g., books, book chapters, government policies, and online reports. With these, the total number of the reviewed and cited references is increased to over 150 .

\section{$4 \quad$ Results}

\subsection{General observations}

In reviewing the literature, technological advancement, policy and legislation analysis, transport modelling and simulation, surveys and interviews, scenario analysis, and case study investigations were found to be the main techniques for qualitative and quantitative analyses in the reviewed 61 papers. These studies are assembled under three broad categories, namely: (a) AV capability—containing 16 studies; (b) AV impact and planning interventions_containing 33 papers; (c) AV policy-containing 12 articles. Review efforts found only 1 paper (peer-reviewed journal article) in the area of planning interventions. This indicates that there exists a gap in the literature in the planning area.

Papers in the AV capability category mainly discussed: (a) How AV operates on public roads; (b) What type of AV capabilities are currently available; (c) What sort of hardware and software are responsible for AV operation; (d) Barriers against the uptake of AV technology; (e) What type of benefits are offered by the AV capabilities.

Articles in the AV impact and planning interventions category mainly elaborated: (a) How perceived value of travel time changes; (b) What type of capacity implications might evolve; (c) How AVs will contribute to reduce road traffic accidents; (d) How AVs might increase or decrease congestion and delay; (e) Whether AVs will enhance or reduce GHG emissions; (f) How employment sector will be affected; (g) How public health can be benefited from AV deployment; (h) How SAVs can contribute in changing car ownership model; (i) How urban land use might be affected due to changes in parking demand, changes in travel time, changes in travel distance; (j) How capital investment decision will be affected. (k) What sort of planning interventions might be required to accommodate disruptions or to control disruptions. The impacts typically cover economic, societal, environmental, and political and governance aspects.

Papers in the AV policy category mainly examined: (a) How conflict can be avoided in between national/federal and state governments in formulating laws; (b) What the jurisdiction of national/federal and state governments should be; (c) How governments, industries, scholars, and professionals can negotiate and agree on formulating laws on liability and privacy; (d) Which organization should standardize or certify technology; (e) Which vehicle should get priority on the road; (f) What should be the new pricing mechanism to manage vehicle kilometers travelled (VKT). 
The reviewed literature, in all categories, illustrate that research on AV is mainly limited to developed countries such as the US, the Netherlands, the UK, Canada, Australia, Israel, Germany, Italy, Singapore, Russia, Poland. This finding shows parallels with the AV piloting and preparing cities listed in Table 1. The oldest article reviewed in this study dates back to 2012 (Smith, 2012). Although there were other articles published prior to 2012, Smith's (2012) paper was the earliest published article that satisfied the selection criteria of this research. The majority of papers were published in 2016 onwards $(84 \%)$ - indicating an exponential growth trend of research on this topic.

\subsection{Capabilities}

According to many, since the invention of the automobile technology about a century ago, the biggest change to personal mobility is happening right now with AVs (Volvo, 2017). In the presence of autonomous driving technology and capabilities, mobility is predicted to be safer, sustainable, and more convenient, as ADS of an AV will replace the human driver for all sort of dynamic driving tasks in some or all roadway and environmental conditions (Shladover, 2018). When AVs attain the capability of replacing human driver, it actually can perform five basic operational functions through its ADS-localization, perception, planning, control, and management (Coppola \& Morisio, 2016; Pendleton et al., 2017). In doing so, $\mathrm{AV}$ s will possess certain technological features, advantages or capabilities over a conventional or human driven vehicle. These include platooning, fuel efficiency, eco-driving, adaptive cruise control with queue assist, crash avoidance, lane keeping, lane changing, valet parking or park assist pilot, traffic sign and signal identification, cyclist and pedestrian detection, and safe maneuvering at intersections (Anderson et al., 2014).

At a particular time, the predicted benefit offered by individual AV feature will largely depend on the AV price, acceptance, operational mode (private or shared), AV share in the traffic mix, level of automation in the traffic mix, and fuel efficiency (Diakaki, Papageorgiou, Papar]michail, \& Nikolos, 2015; Davidson \& Spinoulas, 2016; Daziano, Sarrias, \& Leard, 2017; Piao et al., 2016; Chen, Gonder, Young, \& Wood, 2017). These are seen as the influencing parameters of an AV scenario (Correia, \& van Arem, 2016; Davidson \& Spinoulas, 2016). AVs, however, might present a future full of nightmares resulting from different combinations within these parameters, especially if there do not exist adequate planning interventions.

A summary of the literature in this area is presented in Appendix Table A and discussed below.

- Platooning: Highly random and fluctuating car-following behaviors of human drivers are one of the main factors to prompt accidents, oscillations, and traffic congestion. This results in low efficiency in traffic flows and severe environmental impact in many urban regions (Hoogendoorn, van Arem, \& Hoogendorn, 2014).

To overcome these issues, Gong, Shen and Du (2016) developed a novel platoon carfollowing control scheme that modelled an interconnected dynamic platoon system of CAVs and AVs. Their proposed scheme effectively reduces disturbance transmission of speed errors and relative spacing from the leading vehicle to following vehicles along the platoon. This means that this scheme accomplishes the "string stability" of the platoon. In some other studies, it is also shown that the performance of the conventional cooperative adaptive cruise control (CACC) scheme is outperformed by the developed car-following control scheme in the capacity of achieving stable and smoother traffic flows and traffic oscillations reduction (van Arem, van Driel, \& Visser, 2006; Gong et al., 2016).

With the help of multi-platooning of AVs, Fernandes \& Nunes (2012) performed another study to address the urban traffic congestion issue. In this study, they conceptualized design of a multi-platoon communicant $\mathrm{AVs}$ to travel along a dedicated lane, where AVs can exit from platoons to offline station and merge back into platoons along the main track following novel 
algorithms. According to the algorithms, inter-platoon leaders' constant spacing are ensured and offline station vehicles are allowed to leave and join the platoon on main track cooperatively. Simulation results of several scenarios confirmed that proposed algorithms guarantee high traffic capacity and vehicle density and reduce traffic congestion. Validation results of these features also proved that the proposed algorithms enable a clear benefit of a platooning system in comparison to bus- and light-rail-based transit systems (Fernandes \& Nunes, 2012).

It is observed from the simulation models of Gong et al. (2016) and Fernandes \& Nunes (2012), connectivity among the $\mathrm{AVs}$ within a platoon is a prerequisite to form a stable platoon string.

- Merging or Mandatory Lane Change: Most freeway congestion results from traffic oscillations (or stop-and-go) near freeway ramps, caused by merging activities (Zhou et al., 2017). Freeway sections near ramps are considered as the bottlenecks of the freeway system. In a merging situation, if different ratios of $\mathrm{AV}$ s equipped with longitudinal and lateral detecting technology, and advance cruise control (ACC) are penetrated on freeway with human driven vehicles, cooperative intelligent driver model (CIDM) of AVs could practically improve the freeway performance (Xiao \& Gao, 2010; Zhou et al., 2017). The results from an experiment show that with an increased AV penetration on freeways, standard deviation of speed dispersion or oscillation caused by merged-in vehicle could be reduced progressively, i.e., road safety could be improved. It also shows that when the safe time gap is less than 1.0 second, AVs can improve travel efficiency by minimizing travel time (Zhou, Qu, \& Jin, 2017).

Altche, Qian, and de la Fortelle (2017) assumed a nearer plausible traffic scenario, where all vehicles have semi-autonomous features (ACC, automated braking and accelerating, lane keeping assistance), and are driven by human drivers. In such a scenario, a supervised coordination framework can remove the risk of collision or deadlocks with vehicles arriving from sides, either at intersections or roundabouts, or when merging on freeways (Dresner \& Stone, 2008; Zohdy \& Rakha, 2016). This framework mainly overrides human control inputs when they would become unsafe and create blocked situation in the defined supervisory area at intersections, roundabout, or merging points.

Xie, Zhang, Gartner, \& Arsava (2017) performed an optimization-based ramp control strategy in a CAV and AV environment to evaluate the performance of freeway due to presence of merging vehicle. Results of nine different combination of freeway and ramp vehicle inputs (veh/h) under three ramp control cases demonstrate that "optimal ramp control model" outperforms two other control cases: "gradual speed limit" and "do nothing" with regards to performance measurement indicators - average delay time, vehicle throughput and average speed (Xie et al., 2017). It is observed that all the three types of freeway merging algorithms, mentioned above can improve speed dispersion on freeway, road safety, travel efficiency, congestion level, average delay time, vehicle throughput, and average speed in a merging situation with the help of different level of autonomous features of $A V s$ with or without V2V and V2I connectivity.

- Lane Changing: To progress towards a fully automated highway driving, the riskiest component added to the advanced driver assistance systems (ADAS) of an AV is lane changing maneuver. This maneuver is the riskiest and challenging in the sense that it involves ego vehicle's (vehicle under consideration, i.e., AV in this case) path change in the presence of other moving vehicles all around it as well as it has to consider changes in both the longitudinal and lateral velocity of the ego vehicle (Nilsson, Brannstrom, Coelingh, \& Fredriksson, 2017). During the lane change attempt by a human driver, there are possibilities of collision with at least four vehicles-front and rear vehicles in the same lane, and front and following vehicles in the target lane (Bai, Quan, Fu, Gan, \& Wang, 2017; Nilsson et 
al., 2017). This sort of collisions can be avoided by selecting an inter-vehicle traffic gap and time instance to perform the lane change maneuver by executing a novel lane change maneuver algorithm in a mixed highway traffic environment with both human drivers and AVs with or without V2V and V2I communication (Nilsson et al., 2017), or in an AV only environment through vehicle to vehicle communication among the vehicles (Bai et al., 2017).

The collisions lead to probable consequences of loss of lives and traffic congestion. In addition to that, due to lack of determining a safe inter-vehicle gap and time instance to perform the maneuver, there exists oscillation, travel delay and capacity reduction in traffic flow (Nilsson et al., 2017). Automated lane changes can address about 4-10\% of all accidents that are caused by human error (Luo, Xiang, Cao, \& Li, 2015). Uncoordinated lane-changing and exiting behaviors by $\mathrm{AVs}$ can also considerably interrupt traffic flow by slowing down other vehicles, or even in worse scenario, by inviting accidents (Meissner, Chantem, \& Heaslip, 2016; Talebpour \& Mahmassani, 2016). Cooperative lane-changing of AV can ensure improvement of traffic stability, homogeneity, and efficiency, and reduction in traffic congestion (Nie et al., 2016).

- Valet Parking: Autonomous or valet parking is an obvious component of driver assistance technologies (Brookhuis, de Waard, \& Janssen, 2001; Li \& Shao, 2015). Three sequential steps- circumstance recognition, open-loop (when controller does not require verification of system output or modification of command to the system) motion planning and, closed-loop (information flows around a feedback loop) control execution, are responsible for successful autonomous parking (Lee et al., 2009; Li \& Shao, 2015). AVs will not be capable of delivering its full benefits without having this feature as every trip has to be started from and end at a parking place. Relevant products have already been made available in the market by many of the original equipment manufacturers such as Tesla, Volvo, Audi, BMW, Ford, Land Rover, Mercedes-Benz, Nissan, and Toyota (Li \& Shao, 2015).

Valet or auto-pilot parking features of AVs are expected to find cheap or free parking spaces after dropping off the passenger. This in turn saves travel time or cost for commuters or passengers because the passengers do not require: (a) Cruising for a parking space; (b) Walking to the vehicle to pick up; (c) Paying for costly parking (Zhang, Guhathakurta, Fang, \& Zhang, 2015). Valet parking has also a number of technical advantages over traditional human-driven parking. It is capable of: (a) Avoiding dynamic obstacles; (b) Moving in the narrow passage parking areas; (c) Parking in a narrower space; (d) Ensuring optimization of gear changes; (e) Avoiding crash occurrence; (f) Finding fastest and shortest parking path; (g) Minimizing search time for parking spot (Fagnant \& Kockelman, 2015).

The abovementioned significant AV capabilities have the capacity to induce or affect certain transport system variables (TSV) and as a consequence these variables will disrupt environment, investment, health, employment, infrastructure design, and land-use options. Some of the effects may contribute to the society in a better way, while society may be worse off in others. Timely control of TSV through adoption of short-, mid-, and long-term planning and policy options by concerned national, state and local governments can help in materializing wider AV deployment if this is considered appropriate (Coppola \& Morisio, 2016).

\subsection{Impact and planning interventions}

The extent of AVs' impacts to the society largely depends on their share in the total vehicle fleet (Pinjari \& Menon, 2013; Litman, 2017) and level of the AV uptake and usage differentiated by-(a) Light use: private or shared (Gruel \& Stanford, 2016; Heinrichs, 2016; Dia, \& Javanshour, 2017); (b) Heavy use: bus (Smolnicki \& Soltys, 2016) or freight (Wadud, 2017). Impacts begin with a shift in transport demand and supply variables equilibrium (Childress, Nicholos, Charlton, \& Coe, 2015; Rubin, 2016), necessitating obvious adjustments in planning with new ideas, and innovations (Zakharenko, 2016). 
The impacts, from a system level to societal level may have ripple effect on each other at multiple levels (Milakis, van Arem, \& van Wee, 2017).

The probable areas of influence at a transport system level (either on supply side or demand side), include VKT, PKT, vehicle hours travelled (VHT), value of time (VOT), speed, capacity, headway, traffic flow, delay, travel cost, vehicle operating cost (VOC). These will further affect planning parameters in general such as infrastructure design, transport modelling, capital investment, car ownership, land use, employment, energy consumption, traffic safety and public health, environment (Dixit, Chand, \& Nair, 2016). Planning authorities at local and state levels have to cope with the expected disruption in certain cases and impose planning and policy measures to control rest of the disruptions.

A summary of the literature in this area is presented in Appendix Table B and discussed below.

- Infrastructure Design: Road infrastructure will require new design criteria as lateral and longitudinal capacity of the roadway might be changed due to lane keeping and platooning respectively. Lane width might be reclaimed due to more accuracy in maintaining lateral alignment (Smith, 2012). To improve network performance and vehicle throughput, AVs might require dedicated road network in certain areas (Chen, He, Yin, \& Du, 2017). Considering the impacts on infrastructure design, literature suggests the following planning recommendations (Hendrickson et al., 2014): (a) Pavement marking may require repainting; (b) No changes are expected in the design of clear zone; (c) Radio advisories and ITS message signs may or may not be obsolete depending on the presence of connectivity in automation; (d) Dedicated short range communications (DSRC) locations for traffic signals have to be identified and prioritized in case of automation with connectivity.

- Car Ownership: Flexibility of SAV and its operation would reduce operational and fixed cost and thereby reduce car ownership (Milakis, van Arem, \& van Wee, 2017). The results of an agent-based modelling of different SAV scenarios indicate that each SAV can replace around eleven conventional cars (Fagnant \& Kockelman, 2014). Due to exclusion of driver's talent and time, driverless taxi or autonomous car sharing program paves the way to be a cheaper travel option and may discourage traditional car ownership (Bagloee et al., 2016). Though this may be highly unlikely, some visions of pooled/shared ownership of AVs suggest that there could be no need to own private motor vehicles at all in the future (Levin \& Boyles, 2015) —also see $\mathrm{Ma}$, Zheng, and Wolfson (2015) for a model on real-time city-scale ridesharing. Planners may replace numbers of conventional on-street and off-street parking facilities by ensuring provision of few suburban multistory garages. They may also execute pickup and drop off points for AVs near transport hubs by eliminating existing paid and unpaid parking lots. This will promote tech- and transit-oriented developments (TTOD).

- Employment: Reduction of traffic congestion, travel time savings, and lower transportation costs of goods could be achieved at the expense of individuals, currently employed in building, driving, and maintenance of automobiles (Crayton \& Meier, 2017). Spilling effects in labor market might be a reality due to falloffs in certain related jobs, like diver licensing, traffic policing, and insurance sales (Crayton \& Meier, 2017). Moreover, a future with fewer vehicles would also lead to fewer jobs in the automotive industry as a whole (Snyder, 2016). In contrast, Gill, Kirk, Godsmark, \& Flemming (2015) predicted potential employment gains in three sectors up to $15 \%$ - conversion of parking facilities related construction, roads and highways modification, and IT product and services. State or federal governments might declare rehabilitation package, especially for the abundant drivers of taxi, bus and commercial vehicles. Governments might also arrange specific training depending on the eligibility of drivers so that they can find a job in new sectors. Currently employed automobile technicians and mechanics can be trained up for new technology and this will help them to be remain in the same track without losing job. Automobile industries can also support government's novel initiatives with financial contribution. 
- Energy Consumption and Emissions: Practically, fuel/energy consumption of any transport mode depends on travel activity performed by that mode and energy intensity (consumption per kilometer) of that particular mode, and emission is the product of energy consumption and fuel carbon content (Wadud et al., 2016). Automation might plausibly reduce road transport energy consumption and GHG emissions by approximately half-or nearly double them depending on automation level, AV features, use type, and policy intervention (Wadud et al., 2016).

Litman (2017) predicts that a major share of AVs in road transport will contribute to energy conservation by 2040-2060. Chen, He et al. (2017) indicate that vehicle automation may contribute $45 \%$ savings on fuel consumption in optimistic scenario and $30 \%$ fuel consumption in pessimistic scenario. Another study shows a 37\% of energy savings is possible when AVs are used in conjunction with public transport in lieu of personal car (Moorthy, De Kleine, Keoleian, Good, \& Lewis, 2017). On the other hand, large share of SAV fleet could improve fuel efficiency by abandoning highspeed and rapid acceleration of car (Milakis, van Arem, \& van Wee, 2017). Liu, Kockelman, Boesch, \& Ciari (2017) show that introduction of SAV systems can save $22.4 \%$ of total distance-based fuel consumption and this savings cannot be negated by extra VKT.

Large share of SAV fleet could also limit emissions by abandoning highspeed and rapid acceleration of car (Milakis, van Arem, \& van Wee, 2017). Possibility of total distance-based (lifecycle and driving cycle) savings of GHG emissions is $16.8-42.7 \%$ due to introduction of SAV systems, and this savings cannot be negated by extra VKT due to AV's advancement, eco-technologies, and change in energy source (Liu et al., 2017). Another study in Lisbon city shows that replacement of conventional private car, taxi and bus by self-driving shared taxi and taxi-bus, keeping existing metro service could contribute in reducing carbon emissions (Martinez et al., 2017). It is also estimated that electric driven autonomous taxis could significantly reduce GHG emissions in 2030 with respect to current conventional and hybrid vehicles (Greenblatt \& Saxena, 2015). Smith (2012) predicted reduction of emissions per VKT with an overall increase in total emissions.

It can be summarized that automation related road transport energy consumption and emission figures are still uncertain in their magnitude. This is because energy consumption and emissions are generally not a direct consequence of automation, rather it is affected by changes in vehicle operations, vehicle design, choice of energy, policy intervention, or transportation system design, which are more indirectly facilitated by automation (Wadud et al., 2016). Policymakers probably have to consider VKT based pricing to substitute earlier fuel tax, if energy source is shifted from fossil fuel to electricity. This is a step toward safeguarding government's financial revenue on the eve of electric vehicle. Government can also promote green vehicle operation by allowing less tax on vehicle purchase price and by reducing vehicle registration fee.

- Traffic Safety and Public Health: Until now, no empirical proof is established about the overall safety advantages of AVs (Winkle, 2016). Most of the investigation related to AVs' potential for crash protection was performed considering assumed AV deployment and market penetration scenarios. These assumptions were based on expert estimates, third-party forecasts and relevant database.

The German In-Depth Accident Study (GIDAS) and NHTSA crash databases show approximately $93 \%$ of road crashes happen due to human error, and it has been speculated that this figure might be completely ruled out in case of full automation of vehicles. Even level 0 , and level 1 features of $A V s$ have the potential to minimize one third of the traffic accidents (Bagolee et al., 2016). Daimler, manufacturer of Mercedes-Benz, published a forecasting models on vehicle-safety and crash research in 2010, which suggests increased automation can result in a reduction of crashes by $10 \%$ by $2020,50 \%$ by $2050,71 \%$ by 2060 , and a total reduction by 2070 (Winkle, 2016). A US study projected that conversion of $10 \%$ and $90 \%$ of US vehicle 
fleet to AV would respectively act to reduce annual crashes by 0.2 and 4.2 million, and it could respectively save 1,100 and 21,700 human lives annually (Collingwoood, 2017).

Yet, adjustments of driving behavior in relation to levels 1-3 automation features may invite accidents in many cases (Milakis, van Arem, \& van Wee, 2017). However, new crash risks may emerge due to automated system failures in certain cases, and road users may favor additional risk-taking behavior assuming the AV system's perceived and actual competencies (Litman, 2017). By assuring road safety through higher level of AVs, ripple effect of accident related tangible and intangible costs like medical costs, legal costs, insurance and administrative costs, emergency service costs, workplace losses, and property damages can be minimized (Bagolee et al., 2016). This will help federal or state governments to reconsider their budgets in the near future.

- Capital Investment: AVs might act to reduce proposed existing road expansion investment as platooning might significantly increase road capacity — as much as five times by one source (Fernandes \& Nunes, 2012). That is why, the literature recommends re-evaluating planned road system capacity enhancement projects before making final investment decision. It has also been suggested that ITS and level of service (LOS) investment projects are assessed for compatibility with CAV fleets (Hendrickson et al., 2014).

- Land Use: AVs will either promote urbanization or promote suburbanization. In reality, transport network will tend to flow in between these two scenarios, depending on transport and urban planning policy, prevailing local conditions, and dissemination of different driverless mobility solutions (Smolnicki \& Sołtys, 2016).

At the regional level, accessibility improvements through lower generalized cost of transport due to vehicle automation will result in ex-urbanization to remote areas of former inner city, leading to attractive green urban sprawl surrounding metropolitan regions (Bagolee et al., 2016; Crayton et al., 2017; Milakis, van Arem, \& van Wee, 2017) with lower house prices (Heinrichs, 2016), and decline in rent outside CBD (Zakharenko, 2016). AVs' favor towards urban sprawl may prove transit service superfluous except for dense urban areas (Meyer, Becker, Bösch, \& Axhausen, 2017). Urban sprawl is also subject to availability of land and land-use policies (Yigitcanlar \& Kamruzzaman, 2014; Milakis, van Arem, \& van Wee, 2017).

At the urban/local level, presence of commuting AVs and SAVs (with or without dynamic ride sharing) may free up daytime downtown on-street and off-street parking spaces (Bagolee et al., 2016; Heinrichs, 2016; Zakharenko, 2016; Milakis, van Arem, \& van Wee, 2017). Different spatial distribution of urban parking demand will be evolved against different SAV operation strategies and client's preferences (Zhang et al., 2015). The results of an agent-based model show that the clients adopting SAV system in lieu of conventional private car can eliminate up to $90 \%$ of parking demand at a low market penetration rate of $2 \%$ (Zhang et al., 2015). On the other hand, SAVs have the potential to tackle the transport related-social exclusion (Duvarci, Yigitcanlar, \& MizoKami, 2015; Kamruzzaman, Yigitcanlar, Yang, \& Mohamed, 2016; Yigitcanlar, Mohamed, Kamruzzaman, \& Piracha, 2018).

Driving robots' capability of valet parking may promote neighborhood parking zones or collective garages in the inner-city districts. The presence of auto-valet garages will allow more vehicles to be parked and creates the possibility of increasing density of urban core areas by repurposing released parking spaces due to less demand for parking in CBD areas (Heinrichs, 2016). The saved off-street parking spaces could be repurposed for infill residential and commercial development, allowing increase in economic activity to contribute to the further CBD density (Bagolee et al., 2016; Milakis, van Arem, \& van Wee, 2017), and the saved on-street spaces could be transformed into HOV lanes, bus lanes, cycle lanes, or new public spaces (Milakis, van Arem, \& van Wee, 2017).

Possibility of significant increase in road capacity through platooning - as much as five times (Fernandes \& Nunes, 2012) could save road spaces that might be reallocated to other 
travel modes-like buses, cycling and walking. In an ideal condition, where all the vehicles in roads are fully autonomous, highway capacity might increase around 100\% (Farmer, 2016).

Regulatory body may think about limiting the projected increased AV traffic. Because in presence of public transit, under certain conditions AVs will connect to the transit without entering CBD (Zakharenko, 2016). Local and state government authorities have to decide whether they will allow or limit urban sprawl. It should be exclusively bounded by city's landuse policy. Moreover, most of the state and local authorities should decide reallocation of city's road space and parking spaces depending on nature of travel pattern and traffic behavior in a new form of traffic mix.

Considering too many aspects of AV impacts, Isaac (2016) recommended generalized medium- to long-term planning activities. Medium- and long-term planning activities include: (a) Updating transport model with new assumptions; (b) Forecasting financial revenues; (c) Designating traffic lanes for simultaneous operation of $\mathrm{AV}$ and/or conventional automobile; (d) Updating traffic signs and markings; (e) Reducing lane widths; (f) Adjusting speed limits, traffic signal locations and timing; (g) Eliminating or reducing parking spaces and add more drop off/pick up locations; (h) Reclaiming city center surface parking lots for potential future developments; (i) Reclaiming right-of-way for people and other mode of transport; (j) Doubling use of the suburb on-street parking areas as charging stations; (k) Developing new predictive models for pavement maintenance.

\subsection{Pre-deployment policy}

Higher level of vehicle automation poses regulatory challenges for the AV manufacturing countries (Nowakowski, Shladover, Chan, \& Tan 2015). The uptake of a new technology like AV should be regulated through federal and state governments' pre-deployment policy. Major regulating policies are revolving around testing and deployment, cybersecurity and privacy, liabilities and insurance, ethics, and repair/maintenance and calibration. Proactive actions in this regard may ensure rapid AV uptake in some jurisdictions and reactive or inert actions may delay the whole uptake process in some other jurisdictions. As an example, AV legislation and policies in the US, the Netherlands, the UK and Sweden are paving the way for other countries (Nowakowski et al., 2015, Vellinga, 2017). However, the first fatal crash by a self-driving UBER involving pedestrian in the US proves that more research, development, legislation and planning are needed for a safer and wider AV uptake.

A summary of the literature in this area is presented in Appendix Table $\mathrm{C}$ and discussed below.

- Testing and Deployment: Two main aspects in relation to AV operation, to be bounded by regulation, are testing and deployment. These two main challenges are linked with devising regulations in this particular area to ensure safety without hindering innovation, and defining meaningful requirements or standards without having such technical standards for ADS in place (Nowakowski et al., 2015). Another significant concern focuses on how to maintain legal consistency in different jurisdictions to avoid confrontation with AV manufacturers and to encourage innovation (Vellinga, 2017). Around the globe, policymakers are yet to establish such a consistent legal ground for AV design, testing and deployment. Regulating bodies and practiced legal instruments used by these bodies are also different from each other. Some authorities follow "binding regulation," some follow "non-binding regulation," and some other follow "granting exemption" (Vellinga, 2017).

In the US, technology aspects of vehicle safety are regulated by federal government agency, and other safety aspects related to vehicle registration and driver's training, evaluation, and licensing are the functions of state government (Nowakowski, Shladover, \& Chan, 2016; Vellinga, 2017), but in the UK and the Netherlands, federal government agencies regulate all aspects of vehicle safety for testing and deployment (Vellinga, 2017). Currently, the US federal 
government agency NHTSA and the UK Department of Transport (DoT) is in favor of nonbinding test and deployment regulations for $\mathrm{AV}$ under the cover of national policy and code of practice respectively. On the contrary, one of the US states, California has binding legislations in place to regulate the testing and deployment of AVs. Against the backdrop of binding and non-binding regulations and policy, Dutch Vehicle Authority (RDW) granted exemptions to AV from certain laws under certain conditions.

NHTSA provides guidance for both manufacturers and states, though these are not mandatory to abide by. Manufactures involved in designing, developing, testing and selling should follow the NHTSA policy and guidance to ensure safe testing and deployment of AVs on public roads, and states should follow the policy to prevent inconsistencies in AV laws and regulations among the states. The main exception of the UK Code of Practice over NHTSA policy is that it also addresses the requirements about the test driver. RDW grants the exemption to AV testing on public roads with test specific conditions once all the functionalities to be tested are passed on test track. Both the "binding regulations" and "exemption under conditions" are legally binding for manufacturers to ensure safety during testing (Vellinga, 2017). Though "exemption under conditions" poses legal uncertainty for manufacturers, it flourishes technical developments. On the other hand, non-binding regulation can guide manufacturers or testing organizations to adjust with continuous changes in regulation with advancement in technology (Maurer, Gerdes, Lenz, \& Winner, 2016).

- Privacy and Cybersecurity: AV will essentially be equipped with tracing technology to recognize accident causing factors and consequently to mitigate product liability (Bruin, 2016). At the same time, AV equipped with such technology might have serious impact on information privacy of the persons in side or around such vehicles. Manufacturers should be held responsible if AV fails to comply with laws associated with protection of personal data (Bruin, 2016). Privacy mainly relates to control over autonomy, information, and surveillance when it comes to AV (Glancy, 2012). Personal autonomy is one's ability to make choices independently about oneself. Use of AV inherently affect autonomy by taking over human control in the way people move one place to another (Collingwood, 2017). Personal information privacy can be violated as $\mathrm{AV}$ will collect, store, use, own, transfer, or destroy data/information due to improper or nonexistent disclosure control (Collingwood, 2017).

As an example, transmission of present location, past travel pattern, and future travel plan could compromise privacy of AV user. Personal information collection through comprehensive legal and illegal AV tracking will affect privacy associated with surveillance. To protect the privacy associated with AV, generated data ownership pattern and limit of onward data transmission and its usage have to be finalized in the upcoming data privacy act of different countries. To protect the different privacy interests, legislators and regulators should have answers of following questions - Why it is collected, what will be the uses of personal data. How long data should be preserved. Who can and cannot have access to it. Glancy (2012) argued that, without suitable legal safeguards for privacy, AV could face challenges of "market resistance" from prospective users who recognize $\mathrm{AV}$ as threats to their privacy.

On the other hand, at the advent of increased computerization and networking, AVs are accumulating autonomous capabilities and are inviting cyber-threats as permanent allies (Yagdereli, Gemci, \& Aktas, 2015). One of the main cause of ADS failure is cyber-attacks and software and hardware defects. Hence, this system should be equipped with such defensive system that can respond automatically and dynamically to deliberate and inadvertent attacks and defects (Yagdereli et al., 2015). A cybersecurity system should primarily safeguard on-board data storage, data sharing (Lee, 2017). Cybersecurity concerns should be bounded by regulatory action to protect consumer interests and promote future growth against autonomous unmanned system vulnerabilities. Considering rapid growth and interstate nature of AV tech- 
nology, Lee (2017) emphasizes federal government to take charge of formulating nationwide regulatory framework for communications, privacy, and cybersecurity pertaining to this technology. Within the federal framework, states and industry should conduct experiment and develop self-regulation. In line with formulated regulations AV cybersecurity requirements should be determined and documented in the systems' requirements documents and it should be done before the design of the system (Yagdereli et al., 2015).

- Liability and Insurance: Data obtained through on-board vehicular systems and sensors of ADS can provide sufficient details of an accident to determine many liability decisions with high degree of precision (Dhar, 2016). This will help to identify "at-fault" driver or vehicle and ensure quick processing of insurance payment to victim. This accurate identification of accident related physical factors to environmental factors to human factors would eventually quash delays and litigation costs linked with tort laws and also exclude necessity for no-fault insurance, which is alive at dozens of US states at the moment.

Though emergence of AV makes fault identification accurate and smoother than before, it also raises a big question: who will be held responsible for the accident: driver (till SAE level 3 ), owner, operator, or manufacturer. $\mathrm{ADS}$ of $\mathrm{AVs}$ serve generally a robotic function and raises novel issues in criminal law as robot can malfunction and cause serious harm to people and property. As robotic systems are inappropriate for criminal punishment, humans who produce, program, and deploy robots should be subject to criminal punishment if the robots are intentionally used to cause harm to others (Gless, Silverman, \& Weigend, 2016). However, Gless et al. (2016) advocates in favor of limiting the liability of vehicle operators, if they undermine to initiate reasonable measures to control the risk originated from ADS.

In the US, states are responsible for liability regimes and insurance (Vellinga, 2017). The Californian draft AV Express Terms suggested that the manufacturer should be held responsible in case of collision or accidents caused by AV and that has to be covered by proper insurance. The Dutch law intended to hold the possessor of AV liable for development risks as they cannot invoke the defense that can be called on by the manufacturer (Vellinga, 2017). The UK proposal discussed first party insurance option for the victim but it did not suggest any other substantial changes in liability rules (UK Parliament, 2016). In this case, victim, regardless of liability, can claim from his insurer and later, insurer can recover the amount from the manufacturer-if manufacturer is found liable. Sweden is practicing first party insurance model since 1975 (Schellekens, 2015).

If the liability of human driver or owner of the car would shift to manufacturer in case of collision, this might slow down the progress of AV development (Vellinga, 2017). In addition to this, insurance companies may become less interested to insure the high risk of AVs. This issue can be addressed by limiting the amount of damages one can claim due to the fault of AV. In parallel government could be a reinsurer to encourage the insurance companies to insure AVs (Vellinga, 2017).

\section{$5 \quad$ Discussion and conclusion}

Within the contemporary smart city debate, $\mathrm{AV}$ s represent a way to create an ideal city form and developments in the autonomous driving technology have the potential to bring smart mobility to our rapidly urbanizing world; but for others AV is a branding hoax (Yigitcanlar \& Lee, 2014; Yigitcanlar \& Kamruzzaman, 2018a). Despite a large body of recent literature on AV's, only a limited number of studies have outlined the disruptive effects that AV might bring on city planning and society in general. This paper, through a systematic review of the literature, aimed to determine the current state of research literature on $\mathrm{AV}$ technology, the future direction that this technology is leading to, how the changes are 
likely to affect our day-to-day travel behavior and long-term changes in the structure of our cities, and what would be the likely policy tools for a smooth transitioning of the technology.

As the literature suggests, AVs' major disruptions in our cities will be in urban transport, land use, employment, parking, car ownership, infrastructure design, capital investment decisions, sustainability, mobility, and traffic safety. It is clear from this study that preparing our cities for AVs through progressive planning is critical to achieving the benefits and to address the resulting disruption. On the eve of rising AV demand, local and state governments should be equipped with better policy and planning tools to accommodate $\mathrm{AV}$ technology and its impacts. In parallel, timely interventions from international, national/federal and state levels in terms of regulating, standardizing and certifying this technology and approval of appropriate legislative measures to ensure testing, deployment, privacy, security, and liability issues are addressed. These are discussed in the following sub-sections in detail.

\subsection{Driving forces, uptake factors, impacts and interventions framework}

This paper has investigated the AV phenomenon from the perspectives of AV capability, impact and planning interventions, and pre-deployment policy. Research area covered under this study is only a small part of a broader framework. Based on the findings of the reviewed papers, the study synthesized a broader framework - for AV driving forces, uptake factors, impacts and interventions - illustrated in Figure 1 and discussed below.

Any new innovation demands external thrust or driving forces from social, political, economic, environmental, and technological sectors that might push forward or pull back the key factors responsible for uptake of that very new innovation. With the help of a force matrix, by awarding score against uncertainty and impact of each force, most influential forces behind the key uptake factors can be ranked. Future plausible scenarios of any new technological innovation uptake are the product of multiple combinations of the highly ranked influential driving forces. In the case of AV uptake, relevant driving forces are technological advancements, economic conditions, customer attitudes, environmental conditions, and government policies. Plausible AV scenarios emerged through any two high ranked influential forces might be termed as AVs in boom, in demand, in standby, or in doubt. The prominent uptake factors under any plausible $\mathrm{AV}$ scenario that might lead to changes in values of transport system level variables are AV type, AV growth trend, AV automation level, AV fuel type, AV capabilities, and so on.

Each future plausible AV scenario generally owns a set of AV supply parameters that can act as input parameters for transport modelling. Inclusion of these new modelling input parameters in exist-

ing transport modelling exercise can signify impact of AV uptake patterns through expected changes in output parameters. From the modelling output one can identify the changes in demand parameters from scenario to scenario at transport system level. The demand parameters value might roam around VKT, individual driving speed, per capita distance travelled, per capita generalized cost, per capita travel item, parking demand, per capita travel cost, and mode share by trips. This will dictate the quantitative and qualitative changes in societal parameters — see societal impact box in Figure 1.

Finally, decision-makers and planners have to counteract with intervening planning and policy initiatives in the necessary disruptive areas so that optimum benefits from AV can be realized for a city. In this case, the framework highlights some of the prospective areas of planning and policy interest. These are congestion pricing, lane width reduction, new modelling assumptions, on-street charging points, reduction in on- and off-street parking spaces, introduction of zonal parking garages, adjusting signal location and timings, adjusting speed limits, and optimizing AV share.

As the paper investigated the $\mathrm{AV}$ phenomenon from the perspectives of capability, impact, planning interventions, and pre-deployment policies, it focused on few of the selective parameters from each block of the described framework. In relation to the framework, this paper mainly researched one of the 
driving forces vigorously-pre-deployment government policy. The reviewed pre-deployment government policies are- testing and deployment, privacy and cybersecurity, and liability and insurance. Out of the mentioned uptake and penetration factors, we elaborated the capabilities of AV. The reviewed areas of capabilities are platooning, merging, lane changing, and valet parking. In the area of AV's societal impacts and counter measure to negotiate those impacts, the paper reviewed infrastructure design, car ownership, employment, energy consumption and emission, traffic safety and public health, capital investment, and land use.

By analyzing our research area, it is understood that pre-deployment government policy and AV capabilities have lot of contributions in assuming or estimating transport model input parameters. On the other hand, changes in model output parameters can be directly or indirectly translated into societal impact or disruptions. This will ultimately lead to short-, medium-, and, long-term planning and policy interventions at the local, regional, and state levels to address various disruptions or the impacts of AVs.

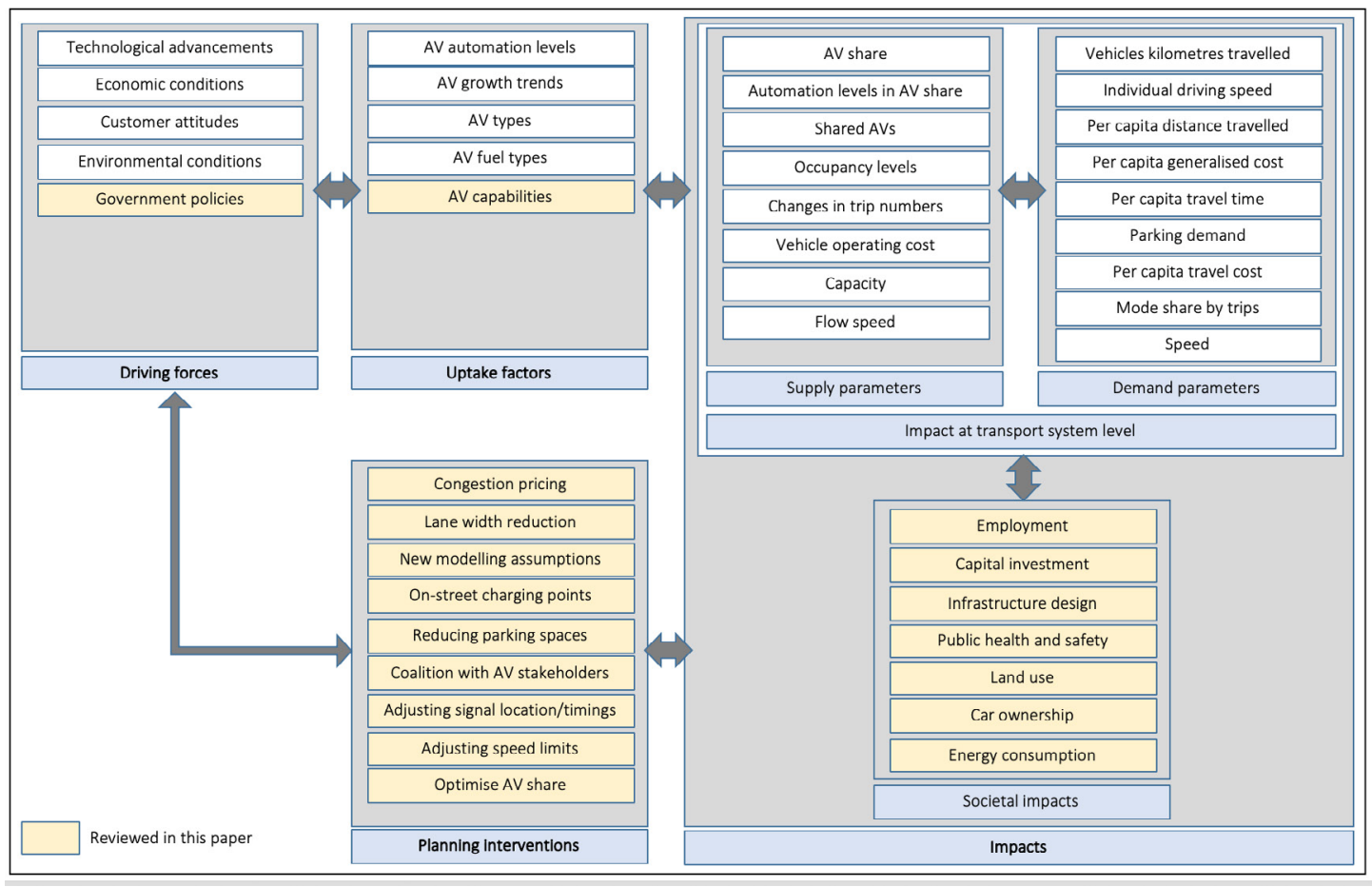

Figure 1. AV driving forces, uptake factors, impacts and interventions framework

\subsection{Research implications}

The review of the literature suggests that most studies to date are optimistic about the potential benefits that $\mathrm{AVs}$ might bring to cities. Rarely have these assumptions been critically examined. In many cases the potential benefits as being advocated are more theory than practice. For example, almost all studies accepted the crash reduction rate (by 90\%) with AVs because human error is responsible for most crashes. They assume that when humans are not in charge of driving, crashes would not happen; a rather heroic assumption. These studies do not consider a myriad of issues that can might cause an AV to be involved in a crash such as software failure, factors that are not included within the AVs' artificial intelligence, failure to recognize a new street layout pattern, and so on.

Additionally, frequently claimed benefits of $\mathrm{AVs}$ in the literature are that they will reduce congestion through optimum use of road spaces using the platooning technology. These studies rarely consider 
the scenario that an effective platooning will only work if all $\mathrm{AVs}$ are travelling from a defined origin to a defined destination in a dedicated lane. However, trip origins and destinations vary from person to person which implies that $\mathrm{AVs}$ will have to frequently change lanes for entry and exit. Moreover, if a non-AV enters into a platoon, the efficiency of platooning will reduce. More importantly, the saved road spaces are likely to be occupied by the induced trips expected to be generated by less mobile people today. Furthermore, the passenger multitasking benefits within AVs may act to increase suburbanization and urban sprawl resulting in additional VKT, and ultimately consume more road space. The prevailing implication that AV's will increase sharing including higher car occupancy also seem weak and should be explored using research on human factors and by investigating AV trial outcomes.

The findings of the review also suggest that effective policy can: (a) Reduce the reliance on traditional vehicles (including AVs); (b) Foster the use of autonomous public transport vehicles (AVPT); (c) Discourage and reduce sprawling development. These are elaborated below:

- In terms of policy to reduce traditional low occupancy private motor vehicle dependency there is a significant supporting literature (Banister, 1997; Newman \& Kenworthy, 1999; Yigitcanlar, Fabian, \& Coiacetto, 2008; Kamruzzaman, Yigitcanlar, Washington, \& Currie, 2014). The policy and planning aspects discussed in the urban and transport planning and urban studies literatures without a specific focus on $\mathrm{AV}$ s are also relevant to the AV context (Firnkorn \& Müller, 2015; Newman \& Kenworthy, 2015). This indicates that there is still a need for further conceptual and empirical explorations for figuring out how to develop and implement AV-related policies and plans to obtain desired outcomes.

- As for the policy to increase the patronage of AVPTs, there is limited research and knowledge. Will the factors (both pull and push) influencing public transport patronage be valid for AVPTs with the widespread deployment of personal AVs or SAVs? The common logic suggests that AVPTs patronage would increase only in the case of convenience of private motor vehicle or private AV is offered. The convenience factors include access to public transport stops (Murray, Davis, Stimson, \& Ferreira, 1998; Yigitcanlar, Sipe, Evens, \& Pitot, 2007), weather and climatic conditions to access and use public transport (Kashfi, Bunker, \& Yigitcanlar, 2015a, 2015b), travel time, cost and in-vehicle conditions (Beirão \& Cabral, 2007). Owczarzak and Zak (2015) built a decision model based on the concept of public transportation on demand based on AVs. They find reliability and safety of AVPTs (unlike traditional determinants such as fare, and travel time) will be the key determinants of user acceptance and thus increased patronage (Lamondia, Fagnant, Qu, Barrett, \& Kockelman, 2016; Becker \& Axhausen, 2017). Similarly, Payre, Cestac, and Delhomme (2014) highlight the importance of acceptance of the technology in its wider roll out. This calls for further empirical investigations both on user confidence and policy formulation aspects of AVPTs.

- In terms of policy to discourage and reduce the sprawling urban development, there is not much research besides some warnings and speculations. For instance, Lari, Douma, and Onyiah (2015) warned us that the decreased travel costs in terms of time and energy (as may be generated by AVs) could result in people living further from urban centers, which would likely to create urban sprawl. The sprawl issue seems to be the biggest challenge for urban policy and planning, hence, there is an urgent need for empirical studies to model the impacts of AVs on our cities, and then develop competent planning policies and actions to address these challenges. Urban policy makers should take this issue seriously.

\subsection{Limitations and research directions}

The following research limitations should be considered: (a) Exclusion of literature outside the peerreviewed full text articles available online, might limit the spectrum of the review as a relatively new field AV research has been mostly published in conference proceedings, book chapters, and white papers; (b) 
Selection of the search keywords might omit inclusion of some relevant literature; (c) The authors' unconscious bias might have an impact on the execution of the review, and interpretation of the findings; (d) The methodological approach is limited to a manually handled literature review technique; further analytical techniques could have been considered — such as scientometrics, content analysis, cognitive mapping, and concept clustering - to generate a clearer picture of the investigated topic.

As indicated by Yigitcanlar, Currie, and Kamruzzaman. (2017), through the convergence of automation, electrification and ride-sharing technologies, AVs could significantly reshape real estate, urban development and city planning - as the automobile did in the last century. This transformation creates an opportunity for planners to make our cities more citizen-centered by bringing back the human-scale and walkable city practices that motor vehicle domination removed. How well prepared are urban planners, however, to mitigate the disruptive impacts on our cities? Do we yet even understand what these disruptions and their implications are? This review of the literature reveals that presently, urban planning as a profession is largely unprepared for AVs. Urban and transport planners need to be aware, smart and proactive about the potential impacts, particularly in terms of the potential for renewed urban sprawl. A future involving widespread use of AVs presents both land-use opportunities and challenges. Progressive outcomes will require an objective assessment of their complex land-use, economic and community influences on our evolving cities. We, hence, advocate the necessity of preparing our cities for AVs and generating desired smart urban mobility outcomes — through appropriate policies, timely legislations, and accurate planning standards and guidelines — even a wider uptake might take quite some time.

\section{Acknowledgements}

This research did not receive any specific grant from funding agencies in the public, commercial or not-for-profit sectors. The authors thank the Editor-in-Chief Prof. David M. Levinson and anonymous referees for their invaluable comments on an earlier version of the manuscript. 


\section{References}

Altche, F., Qian, X., \& De La Fortelle, A. (2017). An algorithm for supervised driving of cooperative semi-autonomous vehicles. IEEE Transactions on Intelligent Transportation Systems, 18, 3527-3539.

Anderson, J. M., Nidhi, K., Stanley, K. D., Sorensen, P., Samaras, C., \& Oluwatola, O. A. (2014). Autonomous vehicle technology. Santa Monica, CA: Rand Corp.

Arbolino, R., Carlucci, F., Cira, A., Ioppolo, G., \& Yigitcanlar, T. (2017). Efficiency of the EU regulation on greenhouse gas emissions in Italy. Ecological Indicators, 81, 115-123.

Arnaout, G., \& Arnaout, J. P. (2014). Exploring the effects of cooperative adaptive cruise control on highway traffic flow using microscopic traffic simulation. Transportation Planning and Technology, 37, 186-199.

Bagloee, S. A., Tavana, M., Asadi, M., \& Oliver, T. (2016). Autonomous vehicles. Journal of Modern Transportation, 24, 284-303.

Bai, W., Quan, J., Fu, L., Gan, X., \& Wang, X. (2017). Online fair allocation in autonomous vehicle sharing. In GLOBECOM 2017-2017 IEEE Global Communications Conference (pp. 1-6), Singapore.

Banister, D. (1997). Reducing the need to travel. Environment and Planning B, 24, 437-449.

Bansal, P., \& Kockelman, K. M. (2017). Forecasting Americans' long-term adoption of connected and autonomous vehicle technologies. Transportation Research Part A, 95, 49-63.

Bask, A., \& Rajahonka, M. (2017). The role of environmental sustainability in the freight transport mode choice: A systematic literature review with focus on the EU. International Journal of Physical Distribution and Logistics Management, 47, 560-602.

Becker, F., \& Axhausen, K. W. (2017). Literature review on surveys investigating the acceptance of automated vehicles. Transportation, 44, 1293-1306.

Beirão, G., \& Cabral, J. S. (2007). Understanding attitudes towards public transport and private car. Transport Policy, 14, 478-489.

Bloomberg. (2017). Is your city getting ready for $A V s$ ? Retrieved from http://avsincities.bloomberg.org/ global-atlas

Boesch, P. M., Ciari, F., \& Axhausen, K. W. (2016). Autonomous vehicle fleet sizes required to serve different levels of demand. Transportation Research Record, 2542, 111-119.

Brereton, P., Kitchenham, B. A., Budgen, D., Turner, M., \& Khalil, M. (2007). Lessons from applying the systematic literature review process within the software engineering domain. Journal of Systems and Software, 80, 571-583.

Brookhuis, K., de Waard, D., \& Janssen, W. (2001). Behavioral impacts of advanced driver assistance systems: An overview. European Journal of Transport and Infrastructure Research, 1, 245-253.

Bruin, R. D. (2016). Autonomous intelligent cars on the European intersection of liability and privacy. European Journal of Risk Regulation, 7, 485.

Burgess, K., Singh, P. J., \& Koroglu, R. (2006). Supply chain management. International Journal of Operations and Production Management, 26, 703-729.

Chang, D. L., Sabatini-Marques, J., da Costa, E. M., Selig, P. M., \& Yigitcanlar, T. (2018). Knowledgebased, smart and sustainable cities. Journal of Open Innovation, 4, 5.

Chen, Y., Gonder, J., Young, S., \& Wood, E. (2017). Quantifying autonomous vehicles national fuel consumption impacts. Transportation Research Part A. doi.org/10.1016/j.tra.2017.10.012

Chen, Z. B., He, F., Yin, Y. F., \& Du, Y. C. (2017). Optimal design of autonomous vehicle zones in transportation networks. Transportation Research Part B, 99, 44-61.

Childress, S., Nichols, B., Charlton, B., \& Coe, S. (2015). Using an activity-based model to explore the potential impacts of automated vehicles. Transportation Research Record, 2493, 99-106.

Chong, Z. J., Qin, B., Bandyopadhyay, T., Wongpiromsarn, T., Rebsamen, B., Dai, P., \& Ang Jr, M. H. 
(2013). Autonomy for mobility on demand. In S. Lee, H. Cho, K. J. Yoon, \& J. Lee (Eds.), Intelligent autonomous systems 12, (pp. 671-682). Berlin: Springer, Berlin.

Christie, D., Koymans, A., Chanard, T., Lasgouttes, J. M., \& Kaufmann, V. (2016). Pioneering driverless electric vehicles in Europe. Transportation Research Procedia, 13, 30-39.

Chun, B. T., \& Lee, S. H. (2015). Review on ITS in smart city. Advanced Science and Technology Letters, 98, 52-54.

Collingwood, L. (2017). Privacy implications and liability issues of autonomous vehicles. Information and Communications Technology Law, 26, 32-45.

Coppola, R., \& Morisio, M. (2016). Connected car. ACM Computing Surveys, 49, 46.

Correia, G. H. de A., \& van Arem, B. (2016). Solving the user optimum privately-owned automated vehicles assignment problem UO-POAVAP: A model to explore the impacts of self-driving vehicles on urban mobility. Transportation Research Part B, 87, 64-88.

Crayton, T. J., \& Meier, B. M. (2017). Autonomous vehicles. Journal of Transport and Health, 6, 245 252.

Creutzig, F., Jochem, P., Edelenbosch, O. Y., Mattauch, L., van Vuuren, D. P., McCollum, D., \& Minx, J. (2015). Transport. Science, 350, 911-912.

Davidson, P., \& Spinoulas, A. (2016). Driving alone versus riding together. Road and Transport Research, 253, 51-66.

Daziano, R. A., Sarrias, M., \& Leard, B. (2017). Are consumers willing to pay to let cars drive for them? Transportation Research Part C, 78, 150-164.

Denaro, R. P., Zmud, J., Shladover, S., Smith, B. W., \& Lappin, J. (2014). Automated vehicle technology. King Coal Highway, 292, 19-24.

Dhar, V. (2016). Equity, safety, and privacy in the autonomous vehicle era. Computer, 49, 80-83.

Dia, H., \& Javanshour, F. (2017). Autonomous shared mobility-on-demand. Transportation Research Procedia, 22, 285-296.

Diakaki, C., Papageorgiou, M., Papamichail, I., \& Nikolos, I. (2015). Overview and analysis of vehicle automation and communication systems from a motorway traffic management perspective. Transportation Research Part A, 75, 147-165.

Dixit, V. V, Chand, S., \& Nair, D. J. (2016). Autonomous vehicles: Disengagements, accidents and reaction times. PLoS One, 11, e0168054.

DoT. (2016). Federal automated vehicles policy: Accelerating the next revolution in roadway safety. Washington, DC: US Department of Transport (DoT).

Dresner, K., \& Stone, P. (2008). A multiagent approach to autonomous intersection management. Journal of Artificial Intelligence Research, 31, 591-656.

Duvarci, Y., Yigitcanlar, T., \& Mizokami, S. (2015). Transportation disadvantage impedance indexing. Journal of Transport Geography, 48, 61-75.

Fagnant, D. J., \& Kockelman, K. M. (2014). The travel and environmental implications of shared autonomous vehicles, using agent-based model scenarios. Transportation Research Part C, 40, 1-13.

Fagnant, D. J., \& Kockelman, K. (2015). Preparing a nation for autonomous vehicles: Opportunities, barriers and policy recommendations for capitalizing on self-driven vehicles. Transportation Research Part A, 77, 167-181.

Fagnant, D. J., Kockelman, K. M., \& Bansal, P. (2015). Operations of shared autonomous vehicle fleet for Austin, Texas, market. Transportation Research Record, 2536, 98-106.

Farmer, D. L. (2016). Autonomous vehicles: The implications on urban transportation and traffic flow theory. Institute of Transportation Engineers Journal, 86, 34-37.

Fernandes, P., \& Nunes, U. (2012). Platooning with IVC-enabled autonomous vehicles: Strategies to 
mitigate communication delays, improve safety and traffic flow. IEEE Transactions on Intelligent Transportation Systems, 13, 91-106.

Firnkorn, J., \& Müller, M. (2015). Free-floating electric carsharing-fleets in smart cities. Environmental Science and Policy, 45, 30-40.

Gill, V., Kirk, B., Godsmark, P., \& Flemming, B. (2015). Automated vehicles. Ottawa: The Conference Board of Canada.

Glancy, D. J. (2012). Privacy in autonomous vehicles. Santa Clara Law Review, 52, 1171-1239.

Gless, S., Silverman, E., \& Weigend, T. (2016). If robots cause harm, who is to blame? New Criminal Law Review, 19, 412-436.

Gong, S., Shen, J., \& Du, L. (2016). Constrained optimization and distributed computation-based car following control of a connected and autonomous vehicle platoon. Transportation Research Part B, 94, 314-334.

Greenblatt, J. B., \& Saxena, S. (2015). Autonomous taxis could greatly reduce greenhouse-gas emissions of US light-duty vehicles. Nature Climate Change, 5, 860-863.

Gruel, W., \& Stanford, J. M. (2016). Assessing the long-term effects of autonomous vehicles. Transportation Research Procedia, 13, 18-29.

Heinrichs, D. (2016). Autonomous driving and urban land use. In: M. Maurer, J. C. Gerdes, B. Lenz, \& H. Winner. (Eds.), Autonomous driving: Technical, legal and social aspects (pp. 213-231). Berlin: Springer.

Hendrickson, C., Biehler, A., \& Mashayekh, Y. (2014). Connected and autonomous vehicles 2040 vision. Harrisburg, PA: Pennsylvania Department of Transportation.

Hoogendoorn, R., van Arem, B., \& Hoogendoorn, S. (2014). Automated driving, traffic flow efficiency and human factors: A literature review. Transportation Research Record, 2422, 113-120.

Isaac, L. (2016). How local governments can plan for autonomous vehicles. In G. Meyer \& S. Beiker (Eds.), Road vehicle automation 3, (pp. 59-70). Berlin: Springer.

Kamruzzaman, M., Yigitcanlar, T., Washington, S., \& Currie, G. (2014). Australian baby boomers switched to more environmentally friendly modes of transport during the global financial crisis. International Journal of Environmental Science and Technology, 11, 2133-2144.

Kamruzzaman, M., Hine, J., \& Yigitcanlar, T. (2015). Investigating the link between carbon dioxide emissions and transport related social exclusion in rural Northern Ireland. International Journal of Environmental Science and Technology, 12, 3463-3478.

Kamruzzaman, M., Yigitcanlar, T., Yang, J., \& Mohamed, A. (2016). Measures of transport-related social exclusion. Sustainability, 8, 696.

Kashfi, S., Bunker, J., \& Yigitcanlar, T. (2015a). Effects of transit quality of service characteristics on daily bus ridership. Transportation Research Record, 2535, 55-64.

Kashfi, S., Bunker, J., \& Yigitcanlar, T. (2015b). Understanding the effects of complex seasonality on suburban daily transit ridership. Journal of Transport Geography, 46, 67-80.

Kim, J., Moon, Y. J., \& Suh, I. S. (2015). Smart mobility strategy in Korea on sustainability, safety and efficiency toward 2025. IEEE Intelligent Transportation Systems Magazine, 7, 58-67.

Krueger, R., Rashidi, T. H., \& Rose, J. M. (2016). Preferences for shared autonomous vehicles. Transportation Research Part C, 69, 343-355.

Lamondia, J. J., Fagnant, D. J., Qu, H., Barrett, J., \& Kockelman, K. (2016). Shifts in long-distance travel mode due to automated vehicles and travel survey analysis. Transportation Research Record, 2566, 1-11.

Lara, A., Costa, E., Furlani, T., \& Yigitcanlar, T. (2016). Smartness that matters: Comprehensive and human-centered characterization of smart cities. Journal of Open Innovation, 2, 8.

Lari, A., Douma, F., \& Onyiah, I. (2015). Self-driving vehicles and policy implications. Minnesota Jour- 
nal of Law Science and Technology, 16, 735.

Lee, C. (2017). Grabbing the wheel early: Moving forward on cybersecurity and privacy protections for driverless cars. Federal Communications Law Journal, 69, 25-52.

Lee, C. K., Lin, C. L., \& Shiu, B. M. (2009). Autonomous vehicle parking using hybrid artificial intelligent approach. Journal of Intelligent and Robotic Systems, 56, 319-343.

Levin, M. W., \& Boyles, S. D. (2015). Effects of autonomous vehicle ownership on trip, mode, and route choice. Transportation Research Record, 2493, 29-38.

Levine, M. L., Segev, L. L., \& Thode, S. F. (2017). A largely unnoticed impact on real estate. Appraisal Journal, 85, 51-59.

Li, B., \& Shao, Z. (2015). A unified motion planning method for parking an autonomous vehicle in the presence of irregularly placed obstacles. Knowledge-Based Systems, 86, 11-20.

Litman, T. (2017). Autonomous vehicle implementation predictions. Victoria, BC: Victoria Transport Policy Institute.

Liu, J., Kockelman, K. M., Boesch, P. M., \& Ciari, F. (2017). Tracking a system of shared autonomous vehicles across the Austin, Texas, network using agent-based simulation. Transportation, 44, $1261-1278$.

Luo, Y., Xiang, Y., Cao, K., \& Li, K. (2016). A dynamic automated lane change maneuver based on vehicle-to-vehicle communication. Transportation Research Part C, 62, 87-102.

Ma, S., Zheng, Y., \& Wolfson, O. (2015). Real-time city-scale taxi ridesharing. IEEE Transactions on Knowledge and Data Engineering, 27, 1782-1795.

Malokin, A., Circella, G., \& Mokhtarian, P. L. (2015). How do activities conducted while commuting influence mode choice? Testing public transportation advantage and autonomous vehicle scenarios. In 94th Annual Meeting of the Transportation Research Board, Washington DC, January 11-15.

Martinez, L. M., \& Viegas, J. M. (2017). Assessing the impacts of deploying a shared self-driving urban mobility system: An agent-based model applied to the city of Lisbon, Portugal. International Journal of Transportation Science and Technology, 6, 13-27.

Maurer, M., Gerdes, J. C., Lenz, B., \& Winner, H. (Eds.). (2016). Autonomous driving: Technical, legal and social aspects. Berlin: Springer.

Meissner, E., Chantem, T., \& Heaslip, K. (2016). Optimizing departures of automated vehicles from highways while maintaining mainline capacity. IEEE Transactions on Intelligent Transportation Systems, 17, 3498-3511.

Meyer, J., Becker, H., Bösch, P. M., \& Axhausen, K. W. (2017). Autonomous vehicles. Research in Transportation Economics, 62, 80-91.

Milakis, D., van Arem, B., \& van Wee, G. (2017). Policy and society related implications of automated driving: A review of literature and directions for future research. Journal of Intelligent Transportation Systems, 21, 324-348.

Milakis, D., Snelder, M., van Arem, B., Homem, G., \& van Wee, G. (2017). Development and transport implications of automated vehicles in the Netherlands. European Journal of Transport and Infrastructure Research, 17, 63-85.

Moorthy, A., De Kleine, R., Keoleian, G., Good, J., \& Lewis, G. (2017). Shared autonomous vehicles as a sustainable solution to the last mile problem. SAE International Journal of Passenger Cars-Electronic and Electrical Systems, 10, 328-336.

Murray, A. T., Davis, R., Stimson, R. J., \& Ferreira, L. (1998). Public transportation access. Transportation Research Part D, 3, 319-328.

Newman, P., \& Kenworthy, J. (1999). Sustainability and cities. New York: Island Press.

Newman, P., \& Kenworthy, J. (Eds.) (2015). The end of automobile dependence. New York: Island Press.

NHTSA. (2016). Federal automated vehicles policy. Retrieved from https://www.transportation.gov/ 
AV/federal-automated-vehicles-policy-september-2016

Nie, J., Zhang, J., Ding, W., Wan, X., Chen, X., \& Ran, B. (2016). Decentralized cooperative lanechanging decision-making for connected autonomous vehicles. IEEE Access, 4, 9413-9420.

Nilsson, J., Brannstrom, M., Coelingh, E., \& Fredriksson, J. (2017). Lane change maneuvers for automated vehicles. IEEE Transactions on Intelligent Transportation Systems, 18, 1087-1096.

Nowakowski, C., Shladover, S. E., Chan, C. Y., \& Tan, H. S. (2015). Development of California regulations to govern testing and operation of automated driving systems. Transportation Research Record, 2489, 137-144.

Nowakowski, C., Shladover, S. E., \& Chan, C. Y. (2016). Determining the readiness of automated driving systems for public operation development of behavioral competency requirements. Transportation Research Record, 2559, 65-72.

Olaverri-Monreal, C. (2016). Autonomous vehicles and smart mobility related technologies. Infocommunications Journal, 8, 17-24.

Oliveira, C. M., Márcio de Almeida, D. A., de Mello, A. L., do Couto Assumpção, F., Dos Santos Gonçalves, F., \& Gonçalves, D. N. (2016). Identificando os desafios e as boas práticas para o transporte urbano de cargas, por meio de uma revisão bibliográfica sistemática. Transportes, 24, 9-19.

Oliveira, C. M., Albergaria De Mello Bandeira, R., Vasconcelos Goes, G., Schmitz Gonçalves, D. N., $\&$ D'Agosto, M. D. (2017). Sustainable vehicles-based alternatives in last mile distribution of urban freight transport: A systematic literature review. Sustainability, 9, 1324.

Owczarzak, Ł., \& Żak, J. (2015). Design of passenger public transportation solutions based on autonomous vehicles and their multiple criteria comparison with traditional forms of passenger transportation. Transportation Research Procedia, 10, 472-482.

Payre, W., Cestac, J., \& Delhomme, P. (2014). Intention to use a fully automated car. Transportation Research Part F, 27, 252-263.

Pendleton, S. D., Andersen, H., Du, X., Shen, X., Meghjani, M., Eng, Y. H., \& Ang, M. H. (2017). Perception, planning, control, and coordination for autonomous vehicles. Machines, 5, 6.

Perveen, S., Yigitcanlar, T., Kamruzzaman, M., \& Hayes, J. (2017). Evaluating transport externalities of urban growth. International Journal of Environmental Science and Technology, 14, 663-678.

Perveen, S., Kamruzzaman, M., \& Yigitcanlar, T. (2017). Developing policy scenarios for sustainable urban growth management. Sustainability, 9, 1787.

Perveen, S., Kamruzzaman, M., \& Yigitcanlar, T. (2018). What to assess to model the transport impacts of urban growth? A Delphi approach to review the space-time suitability of transport indicators. International Journal of Sustainable Transportation. doi.org/10.1080/15568318.2018.1491077

Piao, J., McDonald, M., Hounsell, N., Graindorge, M., Graindorge, T., \& Malhene, N. (2016). Public views towards implementation of automated vehicles in urban areas. Transportation Research Procedia, 14, 2168-2177.

Pinjari, A. R., \& Menon, N. (2013). Highway capacity impacts of autonomous vehicles. Tampa, FL: Center for Urban Transportation Research.

Rowley, J., \& Slack, F. (2004). Conducting a literature review. Management Research News, 27, 31-39.

Rubin, J. (2016). Connected autonomous vehicles: Travel behavior and energy use. In G. Meyer \& S. Beiker (Eds.), Road vehicle automation 3, (pp. 151-162). Berlin: Springer.

SAE. (2016a). Automated driving. Retrieved from https://www.sae.org/misc/pdfs/automated_driving. pdf

SAE. (2016b). Taxonomy and definitions for terms related to driving automation systems for on-road motor vehicles. Retrieved from http://standards.sae.org/j3016_201609

Schellekens, M. (2015). Self-driving cars and the chilling effect of liability law. Computer Law and Secu- 
rity Review, 31, 506-517.

Scheltes, A., \& de Almeida Correia, G. H. (2017). Exploring the use of automated vehicles as last mile connection of train trips through an agent-based simulation model. International Journal of Transportation Science and Technology, 6, 28-41.

Shladover, S. E., Su, D., Lu, X. Y. (2012). Impacts of cooperative adaptive cruise control on freeway traffic flow. Transportation Research Record, 2324, 63-70.

Shladover, S. E. (2018). Connected and automated vehicle systems. Journal of Intelligent Transportation Systems, 22, 190-200.

Smith, B. W. (2012). Managing autonomous transportation demand. Santa Clara Law Review, 52, $1401-1422$.

Smolnicki, P. M., \& Sołtys, J. (2016). Driverless mobility. Procedia Engineering, 161, 2184-2190.

Snyder, R. (2016). Implications of autonomous vehicles: A planner's perspective. Institute of Transportation Engineers Journal, 86, 25-28.

Spyropoulou, I., Penttinen, M., Karlaftis, M., Vaa, T., \& Golias, J. (2008). ITS solutions and accident risks: Prospective and limitations. Transport Reviews, 28, 549-572.

Talebpour, A., \& Mahmassani, H. S. (2016). Influence of connected and autonomous vehicles on traffic flow stability and throughput. Transportation Research Part C, 71, 143-163.

Tranfield, D., Denyer, D., \& Smart, P. (2003). Towards a methodology for developing evidence-informed management knowledge by means of systematic review. British Journal of Management, 14, 207-222.

Trindade, E., Hinnig, M., Costa, E., Sabatini-Marques, J., Bastos, R., \& Yigitcanlar, T. (2017). Sustainable development of smart cities. Journal of Open Innovation, $3,11$.

Truong, L. T., De Gruyter, C., Currie, G., \& Delbosc, A. (2017). Estimating the trip generation impacts of autonomous vehicles on car travel in Victoria. Transportation, 44, 1279-1292.

UK Parliament. (2016). Vehicle technology and automation bill. Retrieved from https://publications. parliament.uk/pa/bills/cbill/2016-2017/0143/cbill_2016-20170143_en_2.htm

van Arem, B., van Driel, C., \& Visser, R. (2006). The impact of co-operative adaptive cruise control on traffic flow characteristics. IEEE Transactions on Intelligent Transportation Systems, 7, 429-436.

Vellinga, N. E. (2017). From the testing to the deployment of self-driving cars. Computer Law and Security Review, 33, 847-863.

Volvo. (2017). Autonomous driving. Retrieved from https://www.volvocars.com/intl/about/our-innovation-brands/intellisafe/autonomous-driving

Wadud, Z., MacKenzie, D., \& Leiby, P. (2016). Help or hindrance? Transportation Research Part A, 86, $1-18$.

Wadud, Z. (2017). Fully automated vehicles. Transportation Research Part A, 101, 163-176.

Walker, W. E., \& Marchau, V. A. (2017). Dynamic adaptive policymaking for the sustainable city. International Journal of Transportation Science and Technology, 6, 1-12.

Winkle, T. (2016). Safety benefits of automated vehicles. In M. Winner (Ed.), Autonomous driving (pp. 335-364). Berlin: Springer.

Xiao, L., \& Gao, F. (2010). A comprehensive review of the development of adaptive cruise control systems. Vehicle System Dynamics, 48, 1167-1192.

Xie, Y., Zhang, H., Gartner, N. H., \& Arsava, T. (2017). Collaborative merging strategy for freeway ramp operations in a connected and autonomous vehicles environment. Journal of Intelligent Transportation Systems, 21, 136-147.

Yağdereli, E., Gemci, C., \& Aktaş, A. Z. (2015). A study on cyber-security of autonomous and unmanned vehicles. Journal of Defense Modeling and Simulation, 12, 369-381.

Yigitcanlar, T., Sipe, N., Evans, R., \& Pitot, M. (2007). A GIS-based land use and public transport ac- 
cessibility indexing model. Australian Planner, 44, 30-37.

Yigitcanlar, T., Fabian, L., \& Coiacetto, E. (2008). Challenges to urban transport sustainability and smart transport in a tourist city. Open Transportation Journal, 1, 19-36.

Yigitcanlar, T., \& Kamruzzaman, M. (2014). Investigating the interplay between transport, land use and the environment: A review of the literature. International Journal of Environmental Science and Technology, 11, 2121-2132.

Yigitcanlar, T., \& Lee, S. (2014). Korean ubiquitous-eco-city. Technological Forecasting and Social Change, $89,100-114$.

Yigitcanlar, T. (2015). Smart cities: An effective urban development and management model? Australian Planner, 52, 27-34.

Yigitcanlar, T. (2016). Technology and the city: Systems, applications and implications. New York: Routledge.

Yigitcanlar, T., Currie, G., \& Kamruzzaman, M. (2017). Driverless vehicles could bring out the best—or worst - in our cities by transforming land use. Retrieved from https://theconversation.com/driverlessvehicles-could-bring-out-the-best-or-worst-in-our-cities-by-transforming-land-use-84127

Yigitcanlar, T., \& Kamruzzaman, M. (2018a). Does smart city policy lead to sustainability of cities? Land Use Policy, 73, 49-58.

Yigitcanlar, T., \& Kamruzzaman, M. (2018b). Smart cities and mobility: Does the smartness of Australian cities lead to sustainable commuting patterns? Journal of Urban Technology. doi.org/10.1080/1 0630732.2018.1476794

Yigitcanlar, T., Kamruzzaman, M., Buys, L., Ioppolo, G., Sabatini-Marques, J., Costa, E., \& Yun, J. (2018a). Understanding 'smart cities': Intertwining development drivers with desired outcomes in a multidimensional framework. Cities, 81, 145-160.

Yigitcanlar, T., Foth, M., \& Kamruzzaman, M. (2018b). Towards post-anthropocentric cities: Reconceptualizing smart cities to evade urban ecocide. Journal of Urban Technology. doi.org/10.1080/106 30732.2018.1524249

Yigitcanlar, T., Mohamed, A., Kamruzzaman, M., \& Piracha, A. (2018c). Understanding transportrelated social exclusion: A multidimensional approach. Urban Research and Policy. doi.org/10.1080 /08111146.2018.1533461

Zakharenko, R. (2016). Self-driving cars will change cities. Regional Science and Urban Economics, 61, 26-37.

Zhang, W., Guhathakurta, S., Fang, J., \& Zhang, G. (2015). Exploring the impact of shared autonomous vehicles on urban parking demand: An agent-based simulation approach. Sustainable Cities and Society, 19, 34-45.

Zhou, M., Qu, X., \& Jin, S. (2017). On the impact of cooperative autonomous vehicles in improving freeway merging. IEEE Transactions on Intelligent Transportation Systems, 186, 1422-1428.

Zohdy, I. A., \& Rakha, H. A. (2016). Intersection management via vehicle connectivity: The intersection cooperative adaptive cruise control system concept. Journal of Intelligent Transportation Systems, $20,17-32$.

\section{Appendix}

Appendix available as a supplemental file at www.jtlu.org/index.php/jtlu/rt/suppFiles/1405/0. 